\title{
The Optimum Equilibrium when Using Experiments in Teaching - Where Virtual and Real Labs Stand in Science and Engineering Teaching Practice
}

\author{
https://doi.org/10.3991/ijet.v14.i23.10890 \\ Ch. Tsichouridis ${ }^{(凶)}$, D. Vavougios \\ University of Thessaly, Volos, Greece \\ hatsihoureuth.gr \\ M. Batsila \\ Ministry of Education, Larissa, Greece \\ G.S. Ioannidis \\ University of Patras, Patras, Greece
}

\begin{abstract}
The present study compares the relative merits of virtual and real educational laboratories in science and engineering education, in terms of their educational effectiveness and if they were the most appropriate for learning. The age of the students was also investigates as a possible factor affecting the outcome. The authors of the present paper started by identifying 67 recent and mutually compatible research papers (articles, doctoral theses, and reviews) and reviewed their content performing a meta-study to discover their findings about the most effective laboratory type. Web-based tools were used, such as ejournals, databases, thematic guides, and portals, catalogues of other libraries offered by a variety of universities. A critical analysis followed to compare findings and reach decisions. In a corollary section of the study, the authors conducted some semi-structured discussions with 25 experienced science teachers of secondary, primary, and tertiary education, for verification purposes. Discussions followed, all participants being arranged in 5 different groups, focusing on still open topics in need of further clarification. The present two-prong analysis resulted in a number of interesting results, presented herein, on the relative effectiveness of virtual and real laboratories as a factor of student age.
\end{abstract}

Keywords-laboratory teaching, virtual labs, real labs, science teaching, metaanalysis

\section{Introduction}

There is a wide variety of educational processes using experiments as a tool in teaching-indeed these are as many as the detailed science and engineering objectives to be taught. Practically, however, all these fall into two general approaches: virtual experiments and real ones, both being in the centre of interest, didactically. Both cate- 
gories are considered important for teaching and learning, and both have been the focus of many research efforts over the past years. Given the wide span of all subjects taught, and the multitude of factors affecting educational effectiveness in each of those, one cannot be surprised that detailed comparisons between these approaches continue being investigated. Indeed, there seems to be a debate as regards the effectiveness of the one over the other category, which is the focus of the present study.

The importance of teaching and learning Science cannot be overemphasized. Teaching natural sciences to all levels of education means setting the aim for learners to explore and study the phenomena that constitute the world around us [1]. Natural sciences do nothing more than actually preparing students of all levels to be creative within a society in which concepts and applications of scientific thinking play an important role for the learners of today and the future [5]. By studying natural sciences, learners can cultivate their knowledge for the world related to their own life context, grow their everyday life skills, and enhance their capacity to acquire the knowledge they will need to meet the challenges of a growing and demanding world [8]. Natural science studies can then teach students the competencies they will need to search for knowledge, encourage them to become scientists themselves and make sense of their world both inside and outside the school walls and institutions. Investigating the natural phenomena, learners learn to apply questions, search for answers, draw conclusions based on data, and communicate their findings with other peers or related audience [22]. Thus, they turn to active and critical thinkers and develop such skills that will lead them to appreciate the accuracy of the observation and description and the ability to plan and test their own solution to a problem while at the same time being able to effectively practice their reasoning skills [31].

By working on natural sciences learners simply get in contact with the spirit of curiosity and argumentation, removing themselves from any prejudiced ideas, thus leading the way to open-mindedness, tolerance, creativity and learning enlightenment [6]. However, in order to employ an appropriate scientific method that will lead to the discovery of new knowledge and its evolution, it seems necessary to follow certain steps and a certain course of action [63]. This begins with the creation of a scientific question or hypothesis, designing and conducting an experiment that will test the case, analyse the raw data acquired to get results, evaluate these results, and interpret them to draw conclusions.

Experimental teaching is considered the most effective method to acquire the above skills. The importance of experiments has been highlighted by many scientists and educators, all of which praise the overall benefits of experiments in science teaching [19]. Thus, according to scientists, experiments lead to acquiring: a) exploratory, organizational and communication skills. b) The ability to process concepts, create hypotheses and use scientific models. c) Cognitive skills, critical thinking, problem solving, application, analysis, and synthesis. d) Understanding the nature of scientific knowledge, the intricacies of the scientific method, as well as appreciating the relationship between science and technology. e) Challenge of interest, initiative support, objectivity of thinking, accuracy of actions, persistence, assumption of responsibilities, consensus, cooperation, communication, and interaction [25]. What is more, scientists claim that experiments offer many benefits that help learners gain the neces- 
sary experience to study the scientific phenomena, deduce concepts of natural sciences by altering or rebuilding their preconceptions, explore and solve everyday problems by developing scientific methodology processes in situations other than the ones in schools [66].

According to literature, experiments offer many benefits and help students learn better, when they are actively involved in learning. This means that they are given the opportunity to use all their senses especially in lab experimental activities that allows them to base their knowledge on a multi-sensory level, enhancing their understanding of concepts they are studying [62]. By engaging in experimental processes, students perceive the phenomena under study and thus they remember better what they learn in contrast to those who are passive listeners-observers, abstaining from the experiential experience. Further to the above, in addition to technical and operational skills gained through experimental tasks, students also have to opportunity to improve their communication skills, given that they learn to cooperate in order to effectively solve a particular problem [68].

There is a wide variety of experimental educational processes - as many as the detailed science objectives to be taught. However, all these fall into two general approaches: virtual experiments and real ones, both being in the centre of interest herein, although remote-online labs represent a separate distinct category. Both categories are considered important for teaching and learning, and both have been the focus of much research over the past years. Given the width of all the subjects taught, and the multitude of factors affecting educational effectiveness in each of those, one cannot be surprised that detailed comparisons between these approaches continue being investigated. Indeed, there seems to be a heated discussion as regards the effectiveness of the one over the other of the categories, which is precisely the focus of the present study.

\section{Purpose of the Research}

The importance of laboratory practice in science studies at all levels of education is acknowledged by the educational research community, while the pedagogical value of the experiments in science teaching is well established. An attempt to detect what category of lab (real or virtual) has better learning outcomes and/or is preferable for science teaching has been reflected in research worldwide. Adopting one method over another has been a matter of heated debate and a great interest has been shown by researchers all over the world regarding their relative educational effectiveness when applied on different age groups, with often-ambiguous conclusions. Indeed, in their final evaluation, some researchers deem imperative to consider not only the increased in-depth knowledge on the Science or Engineering topic being taught, but also the relevant skills students have acquired by performing the experiment - these last being of varied practical relevance in student's future life and profession. Focusing on all these issues and on the need to detect the effectiveness of laboratory work, the authors of the present study decided to investigate the way this heated debate is tilting, by performing a comprehensive comparative meta-study between virtual and real laboratory educational experiments over the past decade. 


\section{$3 \quad$ Methodology}

To investigate and compare any detailed differences in the final effectiveness in terms of learning outcomes of laboratory practice between real and virtual-simulated educational environments, a two-prong approach was followed.

(A). Research papers of the last decade (articles, doctoral dissertations, reviews) related to the comparison of real and virtual workshops in science teaching were looked into in some detail. The basic search tools were web-search tools (e.g. Google Scholar Search Engine), online libraries, electronic journals, databases (EBSCOhost, SCOPUS, Web of Science (Citation Indexes)), electronic books (HEAL- Link, EBSCO), thematic guides and Portals, Catalogues of other Libraries and sites/libraries offered to researchers by collaborating universities. To some extent, this study is a sequel of a larger (albeit solely bibliographical) one examining the relative merits of virtual and real experiments [63]. In that past study, we had focused on a metaanalysis of 106 relevant papers, over a period of the past 40 years. This, however, proved largely inconclusive, revealing no overall winner in the debate while displaying compatible results for either type. It was seen nevertheless, that mostly due to changes in technology, many of the early papers studied might have been outdated, thereby blurring the final conclusions. At the same time, it was suspected that practical educational reasons or other unexpected factors might have seriously affected the final didactical outcome in many cases, hence the introduction of the focused interviewing in the present study.

(B) During the corollary research phase, didactical observations, from 25 experienced teachers from all educational levels, relevant to this long-standing debate concerning the relevant effectiveness of real and virtual laboratory practices were recorded and analysed. All had at least 10 years teaching experience as a prerequisite to participate, and were organised into 5 focus groups, these being suitably small to facilitate free and stimulating discussions. From those, two expert-groups were Primary Education teachers, a further two were from Secondary Education, while a further group was made up of 5 Higher Education teachers.

\section{$4 \quad$ Main Research Results}

The research, which was based on key words and critical analysis, resulted in 67 international research papers implemented from 2010 onward and concerned comparative studies between real and virtual workshops investigating the most effective laboratory environment for the teaching and learning process [1-24], [26-60], [64-70]. It should be noted that particular effort was made to ensure that the papers met the criteria of comparison between groups with the same characteristics, the same methodological teaching approach, and the same duration of lab tasks. The research entailed a meta-analysis of 67 studies that aimed at codifying the findings of each survey and classifying them so that they could be grouped together and interpreted to be ready for comparisons between them. Our research questions focused on: a) Which laboratory environment is more effective in science teaching. b) Which laboratory environment 
is suggested as most appropriate for science teaching and c) Whether or not research conclusions seemed to vary according to the educational level at which they were conducted. In the present study, we will focus on four main categorizations concerning the core of the educational process.

(A) Classification of surveys conducted from 2010 onwards, by education level for the target group that participated in the survey. Specifically, 8 studies $(11.9 \%)$ concerned primary education, $22(32.8 \%)$ secondary education, $31(46.3 \%)$ higher education and $6(9.0 \%)$ secondary education with emphasis on teachers or other educational structures. From what it is observed researchers have focused their interest mainly on groups of secondary and tertiary students $(79.1 \%)$, groups that constitute the core of the educational process (Figure 1).

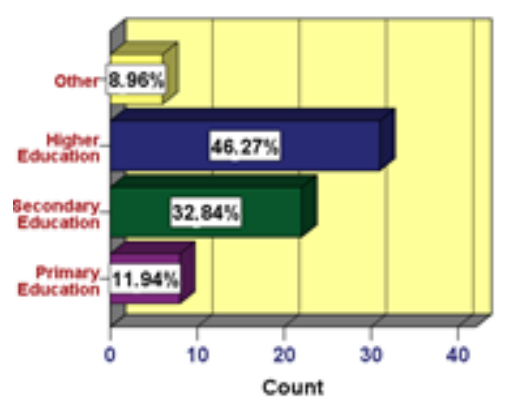

Fig. 1. Classification of papers / surveys according to age of students

(B) Categorization of the most effective educational approach at all three educational levels i) real ii) virtual iii) similar results. It is observed that the majority of researchers $(55.2 \%)$ indicate similar results for both virtual and real labs as they are seen to be equally effective during the learning process. From the rest, virtual labs are seen by a percentage of $23.95 \%$ as the most effective experimental environments and real labs by a percentage of $20.9 \%$ (Figure 2).

(C) Classification of the environment considered as most appropriate for the learning process into three categories

- Real

- Virtual

- Both labs (in combination). 


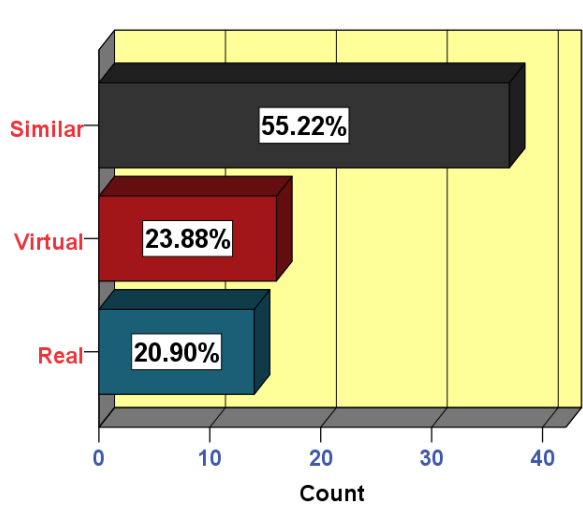

Fig. 2. The most effective experimental environment regarding learning outcomes

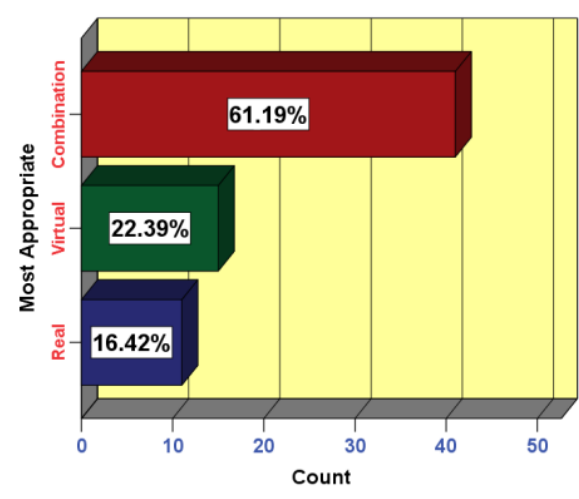

Fig. 3. Experimental environment considered as the most appropriate by researchers

It can be observed that the majority of researchers $(61.2 \%)$ suggested as the most appropriate experimental environment the combination of virtual and real environments, while $22.4 \%$ indicated virtual labs and $16.4 \%$ real labs (Figure 3 ).

An attempt was then made to investigate whether these last two differentiations (i.e. b \& c, above) are statistically significant, and furthermore whether or not they are influenced by the level of education from which the survey sample originates.

The "chi-square" function can be used as a "goodness-of-fit" criterion, that is to interpret if the frequency of occurrence of various ( 3 in this case) categories are compatible with the differences being statistically insignificant. This being called the "null hypothesis", it investigates if it can be seen as likely to have occurred by chance alone, according to a pre-determined threshold probability, i.e. the significance level. By default, the alternative would be if, on the contrary, such distribution of frequencies were unlikely to be due to mere chance. In the present case, as two different parameters are tested, we have two such "alternative hypotheses":

Alternative hypothesis 1: The frequencies of the three levels of the Variable "Most effective experimental environment" (Real, Virtual, Similar) are different from each other, and not appearing so by chance.

Alternative hypothesis 2: The frequencies of the three levels of the Variable "Most appropriate experimental environment" (Real, Virtual, Combination of both) are different from each other. The results in relation to $\chi^{2}$ (as they resulted from the statistical package) are presented as:

- 1: More Effective: $\chi 2(2)=14.537, \mathrm{p}=0.001$

- 2: Most Appropriate: $\chi 2(2)=23.761, \mathrm{p}<0.001$

The values for both factors of $\chi 2$ are statistically significant and we therefore accept the aforementioned alternative assumptions. In conclusion, the findings are sufficient to support (albeit not to prove) that for both variables 1 and 2 the existence of 
maximum values is indeed significant. These are respectively "Similar" in terms of effectiveness, results and "Combination of both labs" in terms of what is most appropriate.

Furthermore, a valid research question would be to investigate if the educationally "optimum practice" may appear to depend on the age of the students (i.e. educational level). To this effect, table 3 contains the primary data concerning the number of relevant papers that are choosing the "most suitable experimental environment", as per the educational level of their survey:

Table 1. The Crossover Table of the Variables "Research educational level" and the "Most Appropriate" and "Most Effective Experimental Approach"

\begin{tabular}{|l|c|c|c|c|c|c|c|}
\hline \multirow{2}{*}{$\begin{array}{c}\text { Types of } \\
\text { Education }\end{array}$} & \multicolumn{3}{|c|}{ Most Effective } & \multicolumn{3}{c|}{ Most Appropriate } & \multirow{2}{*}{ Seal } \\
\cline { 2 - 8 } & Virtual & Similar & Real & Virtual & $\begin{array}{c}\text { Combina- } \\
\text { tion }\end{array}$ & \\
\hline Primary & $4(50 \%)$ & $1(12.5 \%)$ & $3(37.5 \%)$ & $4(50 \%)$ & $1(12.5 \%)$ & $3(37.5 \%)$ & 8 \\
\hline Secondary & $2(9.1 \%)$ & $6(27.3 \%)$ & $14(63.6 \%)$ & $1(4.5 \%)$ & $6(27.3 \%)$ & $15(68.2 \%)$ & 22 \\
\hline Higher & $7(22.6 \%)$ & $8(25.8 \%)$ & $16(51.6 \%)$ & $5(16.1 \%)$ & $7(22.6 \%)$ & $19(61.3 \%)$ & 31 \\
\hline Non specific & $1(16.7 \%)$ & $1(16.7 \%)$ & $4(66.7 \%)$ & $1(16.7 \%)$ & $1(16.7 \%)$ & $4(66.7 \%)$ & 6 \\
\hline Total & $14(20.9 \%)$ & $16(23.9 \%)$ & $37(55.2 \%)$ & $11(16.4 \%)$ & $15(22.4 \%)$ & $41(61.2 \%)$ & 67 \\
\hline
\end{tabular}

From the above table it can be observed that from a total of 67 researchers $55.2 \%$ concluded that the educational effectiveness of real and virtual to be similar. Furthermore, $61.2 \%$ consider that combining both lab types during teaching as the most appropriate approach. This result is seen to be consistent irrespective of student age. When "pressed to choose" researchers are split 23.9 versus $22.4 \%$ in favour of the virtual labs, i.e. roughly equal. A similar, albeit less conclusive, draw (i.e. 23.9 versus $22.4 \%$ in favour of the virtual) is recorded, when researchers choose the "most appropriate" lab. In terms of age variation, the "combination of both" appears to predominate, with notable exception the primary education level, where real experiments still capture researchers favour by a very slim margin. Finally, analysing the "nonspecific" category (i.e. age-independent studies) from the 6 researchers traced, 4 of them have found the combination of the labs to be both effective and appropriate, whereas one of researcher favours real labs, while another discusses virtual labs as being both most effective and most appropriate. (Fig. 4 and 5 respectively). 


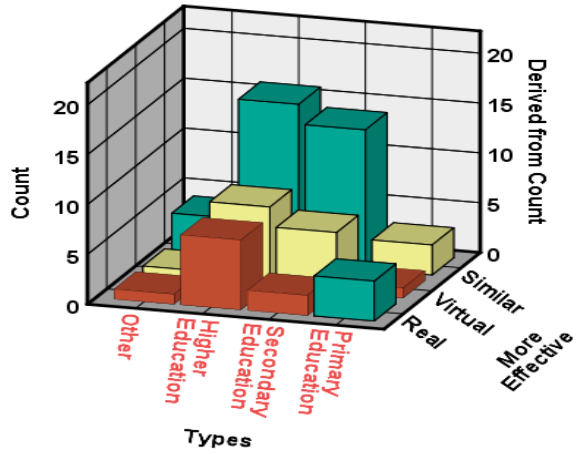

Fig. 4. The most effective environment per type of education by research results

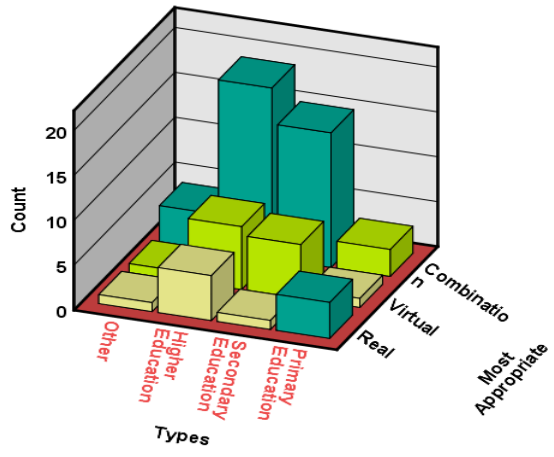

Fig. 5. The most appropriate suggested environment by research results

\section{Corollary Research Results}

As aforementioned, 25 experienced teachers participated, teaching to students of different ages, which were interviewed split in 5 suitably sized expert-groups.

Practical detail considerations relating to everyday use of ICT in education was the first line of information emphatically offered by these participants - strongly based on historic developments. According to them, before 2000 only limited use was made of software in the educational process, as primary and secondary school teachers were not properly trained in ICT use, and ICT equipment in school laboratories was also scarce. Even so, mainly demonstration type software was utilised by a few of the participating teachers acting on their own initiative to improve variety and student interest. From 2000 onwards, as teacher digital retraining gathered momentum, educational software use increased. Discovering their effectiveness in science learning they gradually began using them in teaching, starting with relatively simple applications, and even trying to adapt them to the needs of their students. Educational ICT use was not specified but freedom to the use of "other tools" was offered, all the time having to abide with curricula limitations. Relative lack of suitably organised and supported laboratories persisted in most schools, while software of that period was still somewhat hard to use and complicated, and it therefore remained unpopular. These findings refer to both Secondary and Primary education. Furthermore, software use in primary education was further hampered by the widespread (yet unsupported and irrational) belief that children's experience of the real world should (unquestionably) precede that of the virtual one. Conversely, helped by the fact that adolescents are more enthusiastic and even passionate with digital technology, secondary education science-teachers found it easier to choose and use suitable software in their classes, in parallel to real labs. From 2010 onwards, which the present study investigates, participants claimed that software use was integrated in both primary and secondary educa- 
tion. Its real use gradually increased as curricula clearly encouraged its use in primary and secondary science teaching. In some cases, their use was actively promoted (e.g. in vocational education, mechanical engineering, electronics, electricians, science teaching for special needs education). Gradually, a wide range of software materialised, incorporating digital 3D environments, for all educational levels, in addition to real labs. University students were already familiar with ICT and software use long before their induction in primary and secondary education, but this was mainly true for Engineering and Science departments. Their use expanded in many other departments, even Arts ones (e.g. literature, education pedagogical departments etc.), with ICT courses in all academic curricula. Furthermore, participating university teachers reported both real and virtual lab types being used at universities, for teaching, as well as to offer examples for professional experience.

To proceed further, teacher preferences for each lab type needed to be specifically investigated - for all three educational levels. These were further analysed. Although the majority of primary and secondary education science teachers did not much use virtual labs in the past they started using them during the past few years, helped by their training, curricula flexibility, and their own and their learners' digital familiarization. This was for a variety of science subjects such as physics, chemistry, biology, geography, astronomy, botany, or zoology. In primary education, the majority of teachers argued that, real labs always fascinate young learners, and are easy to be done in class. This, they argue, is because young learners are familiar with real objects in their real life. They, therefore, make the necessary associations to understand the simple phenomena they study: "... they like to bring materials from home when we ask them to and then they go home to show their parents what we did in school", "I always try to link the experiments to things they have in the house ... it's easier for them to understand.." "I like to do experiments with the kids with whatever available in school. Sometimes we use the state software included in our material, and other times we use simple things, real things, like things from the school canteen". However, primary schoolteachers also stated that they also use virtual labs in their classes. This evolved with their own gradual digital familiarization, helped by the everincreasing use of digital technology by young learners. Virtual experiments were selected for the "study of the environment" (age 11-12), involving zoology, and botany, amongst other topics: "We discussed the whales and I took them on a virtual tour to the British Museum of Natural Sciences and we also worked on some interactive software tasks which they enjoyed".

In secondary education both labs are used, but as teachers argue, their students seem to prefer virtual labs rather than real ones. This is "because teens are mainly digitally oriented and like whatever is technology-based". However, although teachers like to be popular, they face a lack of adequate number of computer laboratories in some schools. This problem is further compounded by increased demand for computer-lab use from teachers of other disciplines, creating serious scheduling backlogs. Secondary education students like to work on virtual experiments, paying more attention to them than to real ones. Teachers argue that virtual labs enhance learners' interest, creativity, and curiosity as they see them like their electronic video games. "We do a number or experiments in the school lab but they prefer those virtual ones we do 
in the computer lab...", "I believe they are more satisfied when they do the virtual lab tasks, they are more familiarized with computer instructions and computers in general", "They handle software tasks remarkably! It's more like their games to them...". However, the teachers also mention technology fatigue on behalf of their older teen students (i.e. those in Upper Secondary). As "familiarity breeds contempt", there is a renewed curiosity for real/natural phenomena: "Experiments must follow the theory behind what they study... Students are sometimes bored with software tasks and are curious to see how the experiments work with real equipment; it makes them feel like young scientists".

In tertiary education, on the other hand, university teachers report the use of both types of labs without practical hindrance (adequate equipment, large enough laboratories etc.). Their decision on the type of lab relates to the topic of experimentation while their aim is to use both as a way to supplement each other. They stress that virtual laboratories are common practice in universities although students prefer to have an overview of both types of labs. They also argue that virtual labs are preferred when costly apparatuses are needed, or "dangerous" experiments are involved, but real labs are also needed to familiarize learners with real life future professional tasks and equipment (e.g. mechanics/engineers etc.). In general, teachers report that they do not differentiate one lab from the other and support the fact that both labs are essential to achieve a holistic view of reality as they both display interesting and useful features, suitable for learning.

Finally, teachers at all three educational levels insist that both labs have something different to give and really complement each other and they therefore suggest combined use [65] or sequential one, even switching the order of use from real to virtual and vice versa [67], [69]. This holds not only for a variety of purposes but also for a variety of perspectives of viewing the world: "Students respond to both of them really well and I think with the same interest", "I could not exclude one or the other. I feel they are both important", "There are cases where virtual labs can give us more information when we cannot do an experiment in the real lab but real experiments are also important for student better familiarization with the real world", "Students like variety to maintain their interest". Based on their belief for the superiority of combining both labs, teachers wonder whether virtual reality might be the next step, as it potentially enables learners to view the "deeper reality" through a virtual world, provided that they have features that can simulate natural phenomena as best as possible [61], [62].

\section{Conclusion}

In the present study, the relative educational effectiveness of real versus virtual experiments was examined, using two different research approaches. A comprehensive meta-analysis of 67 compatible papers published during the last 10 years was first performed, comparing real and virtual experimental environments. As a corollary to this, focused semi-structured discussions took place involving groups of expert teachers, experienced in teaching science and engineering subjects (from primary up to 
tertiary level), to gain first-hand knowledge on the practical aspects (and didactic observations) of using both virtual and real lab approaches at school and university.

Based on the findings of the present meta-analysis it may be argued (albeit not conclusively) that young learners of primary education show a preference towards real labs. Virtual labs, on the other hand, outbalance real labs in the interest of teenagers who, although enjoying experimenting with real objects, they are impressed by virtual experiments and simulations that enhance their active participation in learning. Both virtual and real labs seem to be equally preferred by university students, though there is a growing tendency for virtual labs and simulations. In terms of new research in the area, an increasing "trend" of new learning studies (or results) involving virtual environments, from primary to higher education, can be observed. On one hand, this trend derives, from the gradual familiarization and integration of new technologies in schools. Furthermore, this trend "produces" new virtual environments that replace those difficult to implement ones from the past. These cost-effective improvements are largely technology-driven and simulate with increased faithfulness, to the extent that the underlying newer "game technology" allows.

At a corollary level, the present study took into consideration the views of experienced teachers of all three educational levels, not just to investigate practical issues concerning the implementation of various lab types, but to also get their views. Such focus groups discussions (section 5), concur with and confirm the findings of the primary meta-analysis (section 4), presented herein.

Teachers consider that a balanced use amongst both lab types might be the best choice. This is because, on the one hand, real experiments arouse learners' interest in the real and natural world, while on the other hand virtual experiments fascinate them as they now appear familiar with ICT and/or often see them as games. Future students, better acquainted with advanced digital skills, would certainly encourage teachers to alter teaching approaches. Indeed, this would better equip students deal with the augmented-reality or even virtual-reality aspects of their (increasingly remote) workplace tasks. In the near future, nevertheless, teachers (of all levels) will probably continue to use any mix of available laboratory types, in accordance to their educational needs. The exact subject taught, and practical considerations like lab scheduling and suitable software availability will predominate in such decisions.

Looking further into the future, virtual reality with its deep sensory immersion (perhaps involving haptic feedback) is the probable development to today's virtual lab simulations. When combined with artificial intelligence, these could be used for personalized learning to suit the individual cognitive and learning profile of any student (be they from highly gifted ones, and up to special needs). Future development from real labs, on the other hand, is likely to involve augmented reality applications, aided by a variety of sensors embedded in real lab equipment, offering explanations and making suggestions, all the while allowing students to manipulate real equipment. Remote-online labs will probably further improve their human-lab interface using such equipment-embedded sensors, by offering augmented-reality haptics and 3D visuals, thereby merging the educational (and practical) advantages of both approaches. Despite these projected exciting developments for each of the two lab types, the 
question about whose type relative merits prevails still remains in balance, while according to present findings combining both is currently educationally preferable.

\section{References}

[1] Addair, E. (2012). Ceci n' est pas une Mouse-Trap Car: Physical Versus Virtual Materials in the Classroom, Bachelor of Science in Psychology, Carnegie Mello University Pittsburgh, Pennsylvania, U.S., 2012.

[2] Ajredini, F., Izairi, N. \& Zajkov, O. (2013). Real Experiments versus Phet Simulations for Better High-School Students' Understanding of Electrostatic Charging, EJPE, European Journal of Physics Education, 5 (1), pp. 59-70. https://doi.org/10.20308/ejpe.38416

[3] Alkan, F. \& Kocak, C. (2015). Chemistry laboratory applications supported with simulation, Procedia - Social and Behavioral Sciences, 176, pp. 970-976. https://doi.org/10.10 16/j.sbspro.2015.01.566

[4] Atanas, J.P. (2018). Is Virtual-Physical-Virtual Manipulatives in Physics Irrelevant within Studio Physics Environment? Athens Journal of Education, 5 (1), pp. 29-43. https://doi. org/10.30958/aje.5-1-2

[5] Baser M., and Durmus S. (2010). The Effectiveness of Computer Supported Versus Real Laboratory Inquiry Learning Environments on the Understanding of Direct Current Electricity among Pre-Service Elementary School Teachers. Eurasia Journal of Mathematics, Science and Technology Education, 6 (1), pp.47-61. https://doi.org/10.12973/ejmste/75227

[6] Booth, C., Cheluvappa, R., Bellinson, Z., Maguire, D., Zimitat, C., Abraham, J. \& Eri, R. (2016). Empirical evaluation of a virtual laboratory approach to teach lactate dehydrogenase enzyme kinetics, Annals of Medicine and Surgery, 8, pp. 6-13. https://doi.org/10.1016/ j.amsu.2016.04.019

[7] Brodeur, M., Braithwaite, N., Kolb, U. \& Minocha, S. (2015). Improving Undergraduate Engagement with Online Labs; Student Priorities and Strategies for Virtual and Remote Investigations, Selected Papers from the $20^{\text {th }}$ International Conference on Multimedia in Physics Teaching and Learning, September 9-11, 2015, LMU Munich, Germany, pp. 2734.

[8] Carmichael, A., Chini, J.J., Gire, E. \& Rebello, N. S. (2010). Comparing the Effects of Physical and Virtual Experimentation Sequence on Studensts' Understanding of Mechancis, Annual Meeting of the American Educational Research Association, Denver, April 30-May 4, pp. 1-21.

[9] Chini, J.J., Carmichael, A., Rebello, N.S., Gire, E. \& Puntambekar, S. (2010). Comparing Students' Performance with Physical and Virtual Manipulatives in a Simple Machines Curriculum, Annual Meeting of the American Educational Research Association, Denver, April 30-May 4, pp. 1-13.

[10] Crandall, P.G., O’Bryan, C.A., Killian, S.A., Beck, D.E., Jarvis, N. \& Clausen, E. (2015). A Comparison of the Degree of Student Satisfaction using a Simulation or a Traditional Wet Lab to Teach Physical Properties of Ice, Journal of Food Science Education, 14, pp. 24-29. https://doi.org/10.1111/1541-4329.12049

[11] Croom, J.R. (2013). Knowledge Retention for Computer Simulations: A study comparing virtual and hands-on laboratories. Dissertation for the degree of Doctor of Education, Wilkes University, 2013, 190 pages

[12] De Jong, T., Linn, M.C. \& Zacharia, Z.C. (2013). Physical and virtual laboratories in science and engineering education, Science, 340, Special Edition, 19 April 2013, pp. 305308. https://doi.org/10.1126/science. 1230579 
[13] Dimitriou, E., Olympiou, G \& Zacharia, Z. (2012). Investigation of the processes of conceptual understanding of pre-service teachers through the combined use of virtual and real environments of experimentation in light and color, In: K. Tsaggaridou, S. Simeonidou, E. Ftiaka, L. Simeou \& I. Ilia (Eds), Proceedings of the $12^{\text {th }}$ Conference of Pedagogic Association of Cyprus - The assessment and the role of pedagogy: Institutions, Values, Society, Nicosia, June 8-9, 2012, pp. 59-68.

[14] El-Sabagh, H. A. E-A. (2011). The Impact of a Web-Based Virtual Lab on the Development of Students' Conceptual Understanding and Science Process Skills, Degree of Doctor or Philosophy, Faculty of Education, Dresden University of Technology.

[15] Evaggelou, F.V \& Kotsis K., Th. (2012). Comparison of learning outcomes of the Fifth and Sixth grades of Primary students after real or virtual experiments on frictional force, Science and Technology Issues in Education, 5(1-2): 27-43

[16] Evaggelou, F.V. \& Kotsis K., Th. (2014). Comparative study of the impact of real and virtual experiments on water boiling phenomenon with Elementary and Secondary School students, Science and Technology in Education, 7(1-2): 5-24.

[17] Evaggelou, F.V. \& Kotsis K., Th. (2015). Comparison of learning outcomes with elementary school students after performing real and virtual Physics experiments on the reflection of light. In: D. Psillos, A. Molochidis and M. Kalleri (Eds.), Proceedings of the 9th Panhellenic Conference on Science and New Technologies in Education - 'Teaching and learning in the natural sciences and technology: research innovations and practices', Thessaloniki, May 8-10 2015, pp. 520-527.

[18] Evaggelou, F.V. (2012). The Effect of Real and Virtual Physics Experiments on Learning, Doctoral Thesis, University of Ioannina, School of Educational Sciences, Department of Primary Education, Vol A, Ioannina, 2012.

[19] Faour, M.A. \& Ayoubi, Z. (2018). The Effect of Using Virtual Laboratory on Grade 10 Students' Conceptual Understanding and their Attitudes towards Physics, Journal of Education in Science, Environment and Health (JESEH), 4 (1), pp. 54-68.

[20] Farrokhnia M.R. \& Esmailpour A. (2010). A study on the impact of real, virtual and comprehensive experimenting on students' conceptual understanding of DC electric circuits and their skills in undergraduate electricity laboratory. Procedia Social and Behavioral Sciences, 2, pp. 5474-5482. https://doi.org/10.1016/j.sbspro.2010.03.893

[21] Flowers, L. O. (2011). Investigating the Effectiveness of Virtual Laboratories in an Undergraduate Biology Course, The Journal of Human Resource and Adult Learning, 7 (2), pp. 110-116.

[22] Gibbins, L. \& Perkin, G. (2013). Laboratories for the $21^{\text {st }}$ Century in STEM Higher Education. A compendium of current UK practice and an insight into future directions for laboratory-based teaching and learning. The Centre for Engineering and Design Education: Loughborough University, U.K.

[23] Gnesdilow, D., Fathema, N., Lin, F., Kang, S., Dornfeld, C., \& Puntambekar, S. (2016). Exploring Middle School Students' Science Learning and Discourse in Physical and Virtual Labs. In Looi, C.K., Polman, J.L., Cress, U., and Reimann, P. (Eds.). Transforming Learning, Empowering Learners: The International Conference of the Learning Sciences (ICLS) 2016, Vol. 2. Singapore: International Society of the Learning Sciences, pp. 950953. https://doi.org/10.22318/icls2016

[24] Hawkins, I.C. (2013). Part I: Virtual Laboratory versus Traditional Laboratory: Which is More Effective for Teaching Electrochemistry? Part II: The Green Synthesis of Aurones Using a Deep Eutectic Solvent. Degree of Doctor of Philosophy in Math and Science Education, Middle Tennessee State University. 
[25] Hazelkorn, E., Ryan, C., Beernaert, Y., Constantinou, C., Deca, L., Grangeat, M., Karikorpi, M., Lazoudis, A., Casulleras, R.P. \& Welzel-Breuer, M. (2015). Science Education for Responsible Citizenship, Report to the European Commission of the Expert Group on Science Education, Directorate-General for Research and Innovation, Science with and for Society, Luxembourg: Publications Office of the European Union.

[26] Koretsky M., Kelly C. \& Gummer E. (2011). Student Perceptions of Learning in the Laboratory: Comparison of Industrially Situated Virtual Laboratories to Capstone Physical Laboratories, Journal of Engineering Education, 100 (3), pp. 540-573. https://doi.org/10.10 02/j.2168-9830.2011.tb00026.x

[27] Kotsis, K. and Evaggelou, F.V. (2011). Comparison of learning outcomes of elementary school pupils, after real or virtual experiments on the simple electrical circuit In: G. Papageorgiou \& G. Kountouriotis (Ed.), Proceedings of the 7th Panhellenic Conference on Science and New Technologies Education in Education, "Interactions in Educational Research and Practice in Natural Sciences, Volume I, Primary School of Primary Education, Democritus University of Thrace, Alexandroupolis, 15-17 April 2011, pp. 228-237. https:// doi.org/10.33828/sei.v30.i3.4

[28] Marshall, P., Cheng, P. \& Luckin, R. (2010). Tangibles in the balance: a discovery learning task with physical or graphical material, TEI'10 Proceedings of the $4^{\text {th }}$ international conference on Tangible, embedded, and embodied interaction, Cambridge, Massachusetts, USA, January 24-27, pp. 153-160. https://doi.org/10.1145/1709886.1709914

[29] Mutlu, A. \& Şeşen, B., A. (2016). Impact of virtual chemistry laboratory instruction on pre-service science teachers' scientific skills, SHS Web of Conferences, Vol. 26 (01088) 2016, ERPA International Congresses on Education 2015 (ERPA 2015). https://doi.org/10. 1051/shsconf $/ 20162601088$

[30] Naranjo, F. L., Martinez, G., Perez, A., L. \& Pardo, P., J. (2013). Design, development, testing and validation of a Photonics Virtual Laboratory for the study of LEDs, Proceedings of SPIE 9289, $12^{\text {th }}$ Education and Training In Optics and Photonics Conference, 92891T (17 July 2014), Porto, Portugal. https://doi.org/10.1117/12.2070561

[31] Nguen Hoang, Dang Khoa \& Le Cong Nhan (2017). Distinguishing advantages of virtual experiments on solving multiple choice questions in physics test, Proceedings of the $62^{\text {nd }}$ ISERD International Conference, Boston, USA, 14the-15 ${ }^{\text {th }}$ January 2017, pp. 25-27.

[32] Niculae, M, Niculae, C., M. \& Barna, E. (2011). Non-Formal Science Education Promoting Learning Through Experiment, Romanian Reports in Physics, 63 (3), pp. 890-897.

[33] Olympiou, G. \& Zacharia, Z.C. (2010). Physical meets virtual: blending physical and virtual manipulatives to improve understanding in the domain of light and shadows, CBLIS Conference Proceedings 2010, Application of new technologies in science and education, pp. 225-238. https://doi.org/10.1002/sce.20463

[34] Olympiou, G. (2012). Development of a framework of combination of virtual and real environments experimentation in Physics, Doctoral Thesis, Cyprus University, Cyprus, 2012.

[35] Pantoula, Ch., Stavrou, O., Georgopoulos, K. \& Kotsis, K. (2015). Comparison of virtual and real experiments in the teaching of the reconstruction of alternative ideas in the pendulum, In: D. Psillos, A. Molochidis and M. Kalleris (Eds.), Proceedings of the 9th Panhellenic Conference of Science and New Technologies in Education - 'Teaching and learning in natural sciences and technology: research innovations and practices', Thessaloniki, 8-10 May 2015, pp. 402-408.

[36] Paxinou, E., Zafeiropoulos, V., Sypsas, A., Kiourt, C. \& Kalles, D. (2017). Assessing the Impact of Virtualizing Physical Labs, Computer Science, Human-Computer Interaction, pp. 1-5. 
[37] Pearson, C. \& Kudzai, C. (2015). Virtual Laboratories - A Solution for Tertiary Science Education in Botswana? European Journal of Logistics Purchasing and Supply Chain Management, 3 (1), pp. 29-42.

[38] Perez-Garcia S., Hernandez A., B. \& Khotiaintsev S. (2012). Virtual and Real Laboratory for Optical Devices Course in Teaching Telecommunications Engineering. Proceedings of IEEE, Southeaston, 15-18 March 2012, pp. 1-5. https://doi.org/10.1109/secon.2012.619691 $\underline{5}$

[39] Petridou, E., Fotiadou, S., Koukoulas, K. \& Psillos, D. (2015). Real or Virtual Labs? Research in Secondary High School. In: D. Psillos, A. Molochidis and M. Kalleri (Eds.), Proceedings of the 9th Panhellenic Conference of Science and New Technologies in Education - 'Teaching and learning in natural sciences and technology: research innovations and practices', Thessaloniki, 8-10 May 2015, pp. 437-445.

[40] Ranjan, A. (2017). Effect of Virtual Laboratory on Development of Concepts and Skills in Physics, International Journal of Technical Research \& Science (IJTRS), 2 (1), pp. 15-21.

[41] Rau, M.A. (2017). How do Students Learn to See Concepts in Visualizations? Social Learning Mechanisms with Physical and Virtual Representations, Journal of Learning Analytics, 4 (2), pp. 240-263. https://doi.org/10.18608/jla.2017.42.16

[42] Reece, A.J. (2015). An Investigation of the Impacts of Face-to-Face and Virtual Laboratories in an Introductory Biology Course on Students' Motivation to Learn Biology, Dissertation for the degree of Doctor of Philosophy, College of Education and Human Performance, University of Central Florida, Orlando, Florida.

[43] Sanchez Couch, A. (2014). The Impact of Virtual Simulations on Student Comprehension of Mechanics, Master of Natural Science, Graduate Faculty of the Louisiana State University and Agricultural and Mechanical College, Louisiana, U.S.A.

[44] Sarabando, C., Cravino, J.P., Soares, A.A. (2014). Contribution of a computer simulation to students' learning of the physics concepts of weight and mass, Procedia Technology, (13), pp. 112-121. https://doi.org/10.1016/j.protcy.2014.02.015

[45] Sari Ay, O. \& Yilmaz, S. (2015). Effects of Virtual Experiments Oriented Science Instruction on Students' Achievement and Attitude, Elementary Education Online, 14 (2), pp. 609-620. https://doi.org/10.17051/io.2015.25820

[46] Sauter, M., Uttal, D.H., Rapp, D.N., Downing, M. \& Jona, K. (2013). Getting real: the authenticity of remote labs and simulations for science learning, Distance Education, 34 (1), pp. 37-47. https://doi.org/10.1080/01587919.2013.770431

[47] Shimba, M., Mahenge, M.P.I. \& Sanga, C.A. (2017). Virtual labs versus hands-on labs for teaching and learning computer networking: A comparison study, International Journal of Research Studies in Educational Technology, 6 (1), pp. 43-58. https://doi.org/10.5861/ijr set.2017.1660

[48] Smith, G., W. \& Puntambekar, S. (2010). Examining the combination of physical and virtual experiments in an inquiry science classroom, CBLIS Conference Proceedings 2010, Application of new technologies in science and education.

[49] Son, J. Y., Narguizian, P., Beltz, D. \& Desharnais, R.A. (2016). Comparing Physical, Virtual, and Hybrid Flipped Labs for General Education Biology, Online Learning, 20 (3), pp. 228-243. https://doi.org/10.24059/olj.v20i3.687

[50] Sotiriadou, K., Olympiou, G. \& Zacharias, G. (2012). Investigation of the processes of eco-constructing conceptual understanding of pre-service teachers in the context of Light and Color through the use of virtual and real workshops, In: N. Tsaggaridou, K. Mavrou, S. Symeonidou, E. Ftiaka, L. Simeou \& I. Elias (Eds.), Proceedings of the 12th Conference of the Pedagogical Society of Cyprus - 'The Assessment and the Role of Education: Institutions, Values, Society', Nicosia, 8-9 June 2012, pp. 69-78. 
[51] Spyrou, D., Volioti, Ch., Karagiannidis, Ch., Mavropoulou, S. \& Asimopoulos, S. (2015). Comparing the learning outcomes of two teaching procedures, related to sound concepts, to real and virtual learning environments for two teenagers with autistic spectrum disorders, In: D. Psillos, A. Molochidis and M. Kalleri (Eds.), Proceedings of the 9th Panhellenic Conference of Science and New Technologies in Education - 'Teaching and learning in natural sciences and technology: research innovations and practices', Thessaloniki, 8 -10 May 2015, pp. 345-352.

[52] Stamatis, N. K. (2016). Solution preparation and dilution: a case study comparing a virtual and real experiment in the course of Chemistry of the First Lyceum grade, In: Th. Pierratos, P. Koumaras and Ch. Polatoglou (Eds.), Proceedings of the Panhellenic Conference 'Teaching Approaches and Experimental Teaching in Natural Sciences', Thessaloniki, 1617 April 2016, pp. 251-258.

[53] Steger, F., Schweiger, H-G., Nitsche, A. \& Belski, I. (2017). Hands-on Experiments vs. Computer-based Simulations in Energy Storage Laboratories, $45^{\text {th }}$ SEFI Conference, 18-21 September 2017, Azores, Portugal.

[54] Taramopoulos A., Psillos D. \& Hatzikrianiotis E. (2012). Teaching Electric Circuits by Guided Inquiry in Virtual and Real Laboratory Environments. In A. Jimoyiannis (ed). Research on e-Learning and ICT in Education, pp. 211-224. https://doi.org/10.1007/978-14614-1083-6_16

[55] Taramopoulos A., Psillos D. \& Hatzikraniotis, E. (2010). Teaching electrical circuits with a virtual lab and applets of the Open Learning Environment (AMAZ), In: A. Jimogiannis (Ed.), Proceedings of the 7th Panhellenic Conference with International Participation 'ICT in Education', University of the Peloponnese, Corinth, September 23-36, 2010, Vol II, pp. 355-363

[56] Taramopoulos, A. (2012). Investigation of Applications of Simulated Virtual Laboratories in the Teaching of Physics in Compulsory Education, Doctoral Thesis, Aristotle University of Thessaloniki, Pedagogical Department of Primary Education, Thessaloniki 2012.

[57] Taramopoulos, A., Psillos D. \& Hatzikraniotis, E. (2011). Can open virtual environments be used in place of real laboratories? EMA's experience in the field of electricity, In G. Papageorgiou \& G. Kountouriotis (Eds.), Proceedings of the 7th Panhellenic Conference on Science and New Technologies in Education, 'Interactions in Educational Research and Practice in Natural Sciences, Primary School of Primary Education', Democritus University of Thrace, Alexandroupolis , 15-17 April 2011, pp. 679-686. https://doi.org/10.33828/s ei.v30.i3.4

[58] Tatli, Z. \& Ayas, A. (2010). Virtual laboratory applications in chemistry education, Procedia -Social and Behavioral Sciences, (9), pp. 938-942. https://doi.org/10.1016/j.sbspro.20 $\underline{10.12 .263}$

[59] Tatli, Z. \& Ayas, A. (2013). Effect of a Virtual Chemistry Laboratory on Students' Achievement, Educational Technology \& Society, 16 (1), pp. 159-170.

[60] Taveli E., Olympiou G. \& Zacharias Z. (2012). Comparison of the effect of real and virtual experimentation on explanations given by students about phenomena related to the context of Light and Color after forecasting and observation of specific phenomena, In: N. Tsangaridou, K. Mavrou, S. Symeou (Eds.), 12th Conference of the Pedagogical Society of Cyprus, 'The Assessment and the Role of Pedagogy: Institutions, Society Values', Nicosia, 89 June 2012, pp. 79-89.

[61] Tsihouridis, Ch. \& Vavougios, D. (2007). Software through the eyes of students - Evaluating educational software for teaching electrical circuits, Proceedings of the $5^{\text {th }}$ Panhellenic Conference, Physics Science Education and New Technologies in Education, Physics Teaching with New Technology, 5(C), pp. 1104-1113. 
[62] Tsihouridis, Ch., Batsila, M., Vavougios, D. \& Ioannidis, G.S. (2011). Enhancing and assisting laboratory teaching of electrical circuits using ICT: an evaluation of educational software. In Auer M.E. \& Huba M. (Eds). "Academic \& corporate E-Learning in a Global Context" Proceedings of the 14th International Conference on Interactive Collaborative Learning / ICL2011 and the $11^{\text {th }}$ International Conference Virtual University (Vu'11) Piestany, Slovakia 2011, International Association of Online Engineering, IEEE, ISBN 978-14577-1746-8, pp. 323-335. https://doi.org/10.1109/icl.2011.6059599

[63] Tsihouridis, Ch., Batsila, M., Vavougios D. \& Ioannidis, G.S. (2018). The timeless controversy between virtual and real laboratories in science education - "And the winner is...", Chapter in Book. Advances in Intelligent Systems and Computing, Vol 2 of: M.E Auer., D. Guralnick \& I. Simonics, (Eds) Teaching and Learning in a Digital World, Springer International Publishing AG, ISBN 978-3-319-73203-9 DOI: 10.1007/978-3-319-732014-6 20, pp. 1539-1550. https://doi.org/10.1007/978-3-030-11935-5_59

[64] Tsihouridis, Ch., Vavougios, D., \& Ioannidis, G.S. (2013). The effectiveness of virtual laboratories as a contemporary teaching tool in the teaching of electric circuits in Upper High School as compared to that of real labs. In Auer M.E. (Ed) Proceedings of the $16^{\text {th }}$ International Conference on Interactive Collaborative Learning/ICL 2013 \& the $42^{\text {nd }}$ International Conference on Engineering Pedagogy/IGIP 2013, Kazan, Russia 25-27 September 2013, @2014-IEEE, ISBN: 978- 1-4799-0152-4, pp.845-849 . https://doi.org/10.11 09/icl.2013.6644714

[65] Tsihouridis, Ch., Vavougios, D., Ioannidis, G.S., Alexias, A. \& Poulios, S. (2015). Mobile Physics Laboratories as modern study tools in the teaching of electrical circuits: PCB301A case study, Proc. $9^{\text {th }}$ Panhellenic Conference of Science Teaching and New Technologies in Education, May 8-10-2015, Thessaloniki, 7 pages. https://doi.org/10.1109/icl.2015. 7318102

[66] Tsihouridis, Ch., Vavougios, D., \& Ioannidis, G.S. (2016). The Effect of Switching the Order of Experimental Teaching in the Study of Simple Gravity Pendulum - A Study with Junior High School Learners. In (Auer et al. Eds.) Proceedings of $19^{\text {th }}$ International Conference on Interactive Collaborative Learning (ICL2016), and $45^{\text {th }}$ IGIP International Conference on Engineering Pedagogy, 21-23 September 2016, Belfast, pp. 877 - 890. https://doi.org/10.1007/978-3-319-50337-0_47

[67] Tsihouridis, Ch., Vavougios, D., Ioannidis, G.S., Alexias, A., Argyropoulos Ch., \& Poulios, S. (2014). Using sensors and data-loggers in an integrated mobile school-lab setting to teach Light and Optics. In Auer M.E. (Ed.) Proceedings of 2014 International Conference on Interactive Collaborative Learning, (ICL2014), Dubai 3-6 Dec 2014, ISBN: 978-14799-4438-5/14, (O2014-IEEE, pp. 439-445. https://doi.org/10.1109/icl.2014.7017813

[68] Tsihouridis, Ch., Vavougios, D., Ioannidis, G.S., Alexias, A., Argyropoulos Ch., \& Poulios, S. (2015). The effect of teaching electric circuits switching from real to virtual lab or vice versa - A case study with junior high-school learners. In Proceedings of 2015 International Conference on Interactive Collaborative Learning and Engineering Pedagogy (ICL), 20-24 September 2015, Florence, Italy, ISBN: 978-1-4799-8706-1/15 (O2015 IEEE, pp. 634-640. https://doi.org/10.1109/icl.2015.7318102

[69] Ye, W., Wong, N.S. \& Ying Ho, J.W. (2016). Design, Development and Evaluation of Biochemistry Virtual Laboratory for Blended Learning, GSTF Journal on Education (JED), 3 (2), pp. 40-45

[70] Zacharia, Z. C. \& Olympiou, G., (2011). Physical versus virtual manipulative experimentation in physics learning. Learning \& Instruction, 21 (3), pp. 317-331. https://doi.org/10.101 6/j.learninstruc.2010.03.001 


\section{Authors}

Tsihouridis Charilaos, M.Sc, Ph.D, Department of Special Education, University of Thessaly, Argonafton \& Finellinon, 38221, Volos, Greece (e-mail: hatsihour@uth.gr)

Vavougios Dennis, Professor, Department of Special Education, University of Thessaly, Argonafton \& Finellinon, 38221, Volos, Greece (e-mail: dvavou@uth.gr)

Batsila Marianthi, M.Sc, M.Ed, EdD, Directorate of Education, Ministry of Education, Mandilara 23, 41222, Larissa, Greece (e-mail: marbatsila@gmail.com)

Ioannidis George S., Professor, School of Education, University of Patras, 26500 Rion, Greece (e-mail: ioannidis_gs@hotmail.com)

Article submitted 2019-05-18. Resubmitted 2019-07-19. Final acceptance 2019-07-21. Final version published as submitted by the authors. 